\title{
Production of Dental Inlay Wax Using Locally Sourced Materials in Enugu, Nigeria
}

\author{
Peter Chidiebere Okorie ${ }^{1,5, \text { *, John Emaimo }}{ }^{1}$, Cynthia Otitochukwu Aleke ${ }^{1}$, \\ Samuel Chinonyerem Okoronkwo ${ }^{1}$, Godfrey Nwangwu ${ }^{2}$, Kenneth Nkemdilim Okeke ${ }^{3}$, \\ Chibuzor Stellamaris Okonkwo ${ }^{4}$, Emmanuel Chukwuma Obiano ${ }^{5}$ \\ ${ }^{1}$ Department of Dental Technology, Faculty of Health Technology and Engineering, Federal College of Dental Technology and Therapy, \\ Enugu, Nigeria \\ ${ }^{2}$ Dental Technology Unit, Regional Centre for Oral Health Research and Training Initiative, Jos, Nigeria \\ ${ }^{3}$ Department of Dental Technology, School of Health Technology, Federal University of Technology, Owerri, Nigeria \\ ${ }^{4}$ Department of Dental Technology, Shehu Idris College of Health Technology, Markfi, Nigeria \\ ${ }^{5}$ Department of Environmental Health Sciences, Faculty of Health Sciences, Taraba State University, Jalingo, Nigeria
}

Email address:

chidiokorieus@yahoo.com (P. C. Okorie)

${ }^{*}$ Corresponding author

\section{To cite this article:}

Peter Chidiebere Okorie, John Emaimo, Cynthia Otitochukwu Aleke, Samuel Chinonyerem Okoronkwo, Godfrey Nwangwu, Kenneth Nkemdilim Okeke, Chibuzor Stellamaris Okonkwo, Emmanuel Chukwuma Obiano. Production of Dental Inlay Wax Using Locally Sourced Materials in Enugu, Nigeria. International Journal of Dental Medicine. Vol. 5, No. 1, 2019, pp. 1-8. doi: 10.11648/j.ijdm.20190501.11

Received: December 27, 2018; Accepted: January 28, 2019; Published: February 22, 2019

\begin{abstract}
Dental inlay wax is a mixture of several waxes, usually containing paraffin wax, ceresin wax, beeswax and other natural and synthetic waxes. It is used to prepare patterns for gold or other metallic materials in the fabrication of inlays, crowns and bridges. Inlay wax is used for the same purpose as casting wax in the formation of pattern mostly for metallic casting in Dental technology. This study aimed at producing dental inlay wax using locally sourced materials in Enugu, Nigeria. The research was carried out between July to September, 2018 in Enugu, Nigeria. The study adopted a three phased experimental approach using the same procedures but different weight compositions. Structured, pretested Product Evaluation Data Sheet was used to evaluate the product by selected Practicing Dental Technologists in Enugu State, Nigeria. The resultant wax from experiment III with the following composition: $60 \mathrm{~g}$ Paraffin wax, $5 \mathrm{~g}$ Beeswax, $25 \mathrm{~g}$ Carnauba wax, $10 \mathrm{~g}$ Ceresin wax and $(35 \mathrm{~g})$ of green ketchup colorant gave the best result. Its properties are comparable to the conventional Dental Inlay wax. There was significant agreement among the respondents in the smoothness of the product (40\%); excellent dimensional stability and product effectiveness (40\%); flow and burnout of the product (35\%), and color stability of the product (45\%). These findings suggests that dental inlay waxes can be produced locally in Enugu, Nigeria. Therefore, more attention needs to be paid in the production process, which will facilitate easy practice of Dental Technology, and also conserve huge foreign exchange being spent in the importation of inlay wax in Nigeria.
\end{abstract}

Keywords: Carnauba Wax, Ceresin Wax, Dental Materials, Inlay Wax, Paraffin Wax

\section{Introduction}

In Dental Technology practice, only few procedures can be completed without the use of wax in one of its many forms [1]. It has been difficult to define wax. However, William (2012) defined "wax" in chemical term, which was derived from the Anglo-Saxon word "weax" for beeswax practically as a substance similar in composition and physical properties to beeswax [2]. Manappallil (2003) also defined wax as a variety of products of thermoplastic nature for all those uses where there is a necessity for a material that is soft and easy to model that becomes rigid and stable with cooling [3].

Waxes exist in form of natural and synthetic substances. The natural ones can be divided into renewable and nonrenewable. The renewable waxes are re-growing and can be 
either chemically unmodified vegetable and animal based or can be chemically modified for instance, the hydrogenated or re-esterified types. Synthetic waxes exist as homo-polymers and co-polymer [4]. In application, waxes are used in many fields of endeavor but are paramount in the field of Dental technology. Dental waxes are thermoplastic modeling materials that are solid at room temperature [5]. Dental waxes are always mixture of compounds with various melting points. The mechanical behavior is therefore temperature sensitive, depending on composition and number of phases [6]. However, the utility of dental waxes stems from several factors: they are cheap, non-toxic, low melting, weak solid that can be readily shaped and molded. They are important in the construction of prosthetic appliances, and in ensuring highest precision work in dentistry.

Dental waxes vary in characteristics as well as in qualities such as hardness, ductility and melting point [7]. The physical properties of waxes are diverse but all waxes share the properties of having a melting temperature range, the tendency to flow, the ability to harbor residual stresses and having the largest thermal expansion of all dental materials [8]. Dental waxes are supplied in different types, with each designed for specific purposes: these waxes includes but not limited to Baseplate wax, Occlussal Registration wax, Indicator wax, Sticky wax, Utility wax, Inlay wax, Boxing wax, and Corrective wax [9].

Dental inlay waxes are type of pattern waxes used during pattern making for cast restorations. Cast restorations like inlays, crowns and bridges are cast using various metals and alloy through a lost wax technique. Wax pattern is first prepared in inlay wax to duplicate the shape, size and contour of the desired metal casting [10,11]. The knowledge and proper manipulation of dental inlay waxes is critical to ensure that these properties do not interfere with the success of final dental restoration; inlay wax is a very essential material in dentistry, it comes in wide variety of shapes blocks, sheets, rod and tube and appear smooth [12].

According to Baker (2002), waxes used in the production of inlay wax are classified according to their source. Thus; (i) Plant wax - carnauba wax, candelilla wax, (ii) Animal wax bees wax, shellac wax, tallow fat, (iii) Petroleum wax paraffin wax, microcrystalline wax, (iv) Mineral wax ceresin wax, montan wax. Therefore, the essential ingredients for a successful inlay wax are: paraffin wax, carnauba wax, ceresin wax, bees wax, and colourant [13].

Paraffin wax is classified as a natural wax under petroleum wax. It is obtained principally from the high boiling point fractions of petroleum. It is composed mainly of a mixture of hydrocarbon, mixtures of alkanes usually in homologues series of long chain length. The melting point ranges from $40^{\circ} \mathrm{C}$ to $70^{\circ} \mathrm{C}$ depending on the molecular weight. On cooling and solidification it shrinks from 11 to 15 percent. Presence of oil in the waxes lowers the melting temperature; paraffin wax used in dentistry is usually refined and has less than $0.5 \%$ oil which can lower the melting temperature [1]. Paraffin wax produced by current refining procedure can crystallize in the form of plates, needles or malcrystals, but are usually of plate type. Many hydrocarbon waxes undergo crystalline changes on cooling, and a transition from needles to plates occurs about $5^{\circ} \mathrm{C}$ to $8^{\circ} \mathrm{C}$ below their melting temperature [14].

Ceresin wax is classified as a natural wax under mineral wax, a term used to describe waxes from wax bearing distillates from natural-mineral petroleum refining or lignite refining. Like microcrystalline waxes, it has higher molecular weight and greater hardness than hydrocarbon waxes distilled from crude products. These waxes also may be used to increase the melting range of paraffin wax [1].

Carnauba wax is composed of straight chain esters, alcohols, acids and hydrocarbons. It is characterized by high hardness, brittleness and high melting temperature. Carnauba waxes possess an outstanding quality of increasing the melting range and hardness of paraffin wax [1]. However, in conditions of unavailability of carnauba wax, tallow fat (stearic acid) can be used as substitute. Stearic acid is a saturated fatty acid with an 18-carbon chain and has the IUPAC name Octadecanoic acid with chemical formula $\mathrm{CH}_{3}\left(\mathrm{CH}_{2}\right)_{16} \mathrm{COOH}$. It is a white waxy solid with a pungent smell, density of $0.9408 \mathrm{~g} / \mathrm{cm}^{3}\left(20^{\circ} \mathrm{C}\right), 0.847 \mathrm{~g} / \mathrm{cm}^{3}\left(70^{\circ} \mathrm{C}\right)$, and a melting point of $69.3^{\circ} \mathrm{C}\left(156.7^{\circ} \mathrm{F} ; 342.4 \mathrm{~K}\right)$. It derives its name from the Greek word "stear", which means tallow. The salts and esters of stearic acid are called stearates [15].

Beeswax is also a natural wax from animal origin. It is produced in the beehive of honey bees of the genus Apis. It is mainly esters of fatty acids and various long chain alcohols [1]. Beeswax used in dentistry is a complex mixture of esters consisting mainly of myricyl palmitate plus saturated and unsaturated hydrocarbons and high molecular weight organic acids. Beeswax has a relative low melting point range of $62^{\circ} \mathrm{C}$ to $64^{\circ} \mathrm{C}\left(144^{\circ} \mathrm{F}\right.$ to $\left.147^{\circ} \mathrm{F}\right)$ [21]. If beeswax is heated above $85^{\circ} \mathrm{C}\left(185^{\circ} \mathrm{F}\right)$ discoloration occurs. The flash point of beeswax is $204.4^{\circ} \mathrm{C}\left(400^{\circ} \mathrm{F}\right)$. Density at $15^{\circ} \mathrm{C}$ is $958 \mathrm{~kg} / \mathrm{m} 3$ to $970 \mathrm{~kg} / \mathrm{m} 3$ [21, 22]. The taste of beeswax is normally pleasant and is not specific - any unpleasant taste is a sign of quality deterioration due to foreign matter. Odour should be pleasant and honey-like [22].

Coloring agents are chemicals and substances that impact colour including soluble dyes and insoluble pigments. They are used in inks, paints and as indicator and reagents. Some of the substances that carry out these functions are malachite green, brilliant cresyl blue, and methyl green etc.

Considering the impacts of importation of various dental waxes and especially inlay wax on the economy of Nigeria as a nation, production of dental inlay wax using locally sourced materials in Enugu, Nigeria has become paramount.

\section{Materials and Methods}

\subsection{Study Area}

The study was conducted at the Federal College of Dental Technology and Therapy, Enugu, Nigeria. The raw materials were sourced from the state. Enugu state is one of the 36 states in Nigeria. Located in the southeastern part of the country, Enugu spreads its borders to the states of Kogi and Benue to 
the north, Ebonyi to the east, Abia and Imo to the south and Anambra to the west, covering an area of around $8,730 \mathrm{~km}^{2}$.

Its landscape changes from tropical dense rain forest in the south to small round-topped hills covered by open grasslands with occasional clusters of woodland in the middle to sometimes almost sandy savannah in the north. The state includes most of the Udi-Nsukka plateau, a pair of plateaus that form a nearly continuous elevated area. The Nsukka plateau extends about $130 \mathrm{~km}$ from Nsukka in the north, to Enugu in the south and continues southward for about 160 $\mathrm{km}$ to Okigwe. It rises more than 300 metres and its highest part is found $20 \mathrm{~km}$ northwest of Enugu. The steep slopes form spectacular views of the hills and lowlands, broken up by numerous streams and rivulets feeding the Niger and Benue rivers.

Christianity is the major religion, mostly due to the history of contact with the west in the pre-colonial period. Farming and trading constitute the key occupations in the state's economy: yam, cassava and palm-oil produce are the main crops, but corn, rice, pumpkin, melon, beans, okra, avocado, pineapple and even cashew nuts are cultivated as well. Besides coal, new mineral deposits have recently been discovered in Enugu State. These include limestone, iron ore, crude oil, natural gas and bauxite.

\subsection{Study Design}

This study is an Experimental Study design that focuses on the production of dental inlay wax using locally sourced materials in Enugu, Nigeria.

\subsection{Raw Materials and Production Mould}

Paraffin wax, Bees wax, Ceresin wax, Carnauba wax and Coloring agent (malachite green and brilliant cresyl blue) flakes used were purchased from Ogbete Market in Enugu Metropolis, Enugu state, Nigeria. The mould (Figure 1) was fabricated at the Coal Camp Industrial layout, Enugu, Nigeria.

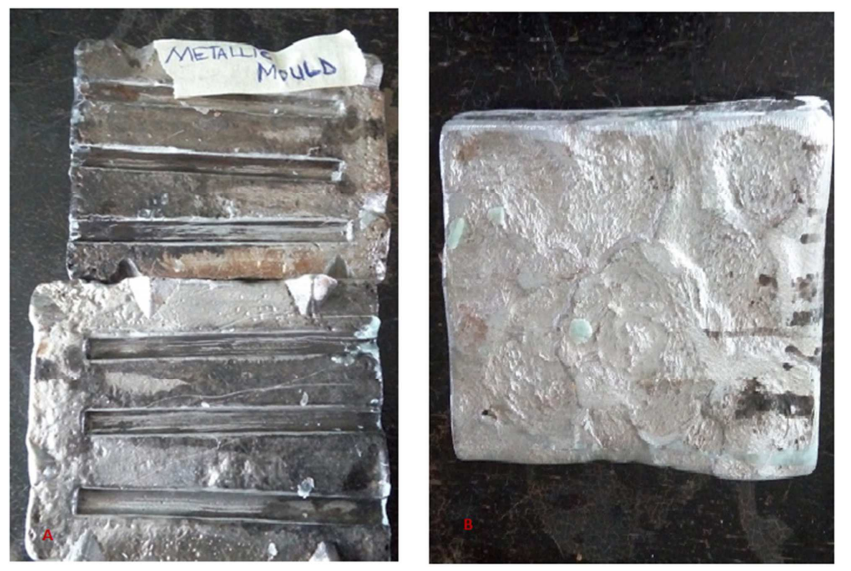

Figure 1. Mould for the inlay wax: (A) open; (B): closed.

\subsection{Preparation of Wax Samples}

All materials were cut into small pieces and put into a measuring beaker in order to be heated to the experimental temperature. A water bath was used as the heating medium. This facilitates uniformity of the heating of materials and to ensure maintenance of wax temperature. The measured waxes were heated in the water bath until all materials melt into a homogenous liquid. The coloring agent was then add to the homogenous mixture and stirred at the experimental temperature for about 10 minutes. This helps elimination of air bubbles which can interfere with the production results. The sequence of dissolution of the constituents was closely observed. The mixture was then poured into the mould and allowed to solidify.

\subsection{Production Process}

Experiment I: The raw materials used in this experiment were weighed to the following specifications paraffin wax $50 \mathrm{~g}$, bees wax $10 \mathrm{~g}$, carnauba wax $20 \mathrm{~g}$, ceresin $20 \mathrm{~g}$, colorant $35 \mathrm{~g}$. These weighed materials were put into a glass beaker and heated in water bath. The melting temperature of each constituent material was closely observed and recorded.

Experiment II: In this experiment, all the raw materials were weighed according to the following specifications: paraffin wax $40 \mathrm{~g}$, bees wax $20 \mathrm{~g}$, carnauba wax $20 \mathrm{~g}$, ceresin $20 \mathrm{~g}$, colorant $35 \mathrm{~g}$. Similar procedures as in experiment I were followed.

Experiment III: In this experiment, the raw materials were weighed according to the following specifications: paraffin wax $60 \mathrm{~g}$, bees wax $50 \mathrm{~g}$, carnauba wax $25 \mathrm{~g}$, ceresin $10 \mathrm{~g}$, colorant $35 \mathrm{~g}$. Similarly, the procedures as in experiment I were followed.

\subsection{Kinetic Studies}

The effects of dimensional changes, burnout ability, melting range and flow ability was determined using the standard procedure.

\subsection{Statistical Analysis}

Data from the Product Assessment Form distributed to practicing dental technologists in Enugu State who are the end users of inlay wax were analyzed using SPSS Statistics version $20^{\circledR}$ and presented using frequency tables and percentages, and figures.

\section{Results}

Production of dental inlay wax in the Dental Technology Laboratory of Federal College of Dental Technology and Therapy, Enugu was done in three (3) experimental stages using petroleum wax (Paraffin wax), mineral wax (ceresin wax), animal wax (bees wax), plant wax (carnauba wax) and coloring agent.

Tables 1, 2 and 3 below present the experimental materials and quantity, procedures and observations of the three (3) phases of experiment in the production of the inlay wax. 
Table 1. Experiment I.

\begin{tabular}{|c|c|}
\hline Experiment Procedures & Observations \\
\hline $\begin{array}{l}\text { Pre-weighed quantities of paraffin wax, beeswax, ceresin wax and } \\
\text { carnauba wax were cut into smaller sizes and put together in a } \\
\text { beaker. They were subsequently heated in a water bath }\end{array}$ & $\begin{array}{l}\text { Paraffin wax was first to melt at the temperature of } 58^{\circ} \mathrm{C} \text {, followed by ceresin wax } \\
\text { at the temperature range of } 61^{\circ} \mathrm{C}\left(141.8^{\circ} \mathrm{F}\right) \text { to } 65^{\circ} \mathrm{C} \text {. Beeswax also melted at the } \\
\text { same range as the ceresin but was significant at exactly at the temperature of } 63^{\circ} \mathrm{C} \\
\left(146^{\circ} \mathrm{F}\right) \text {. The last to melt was Carnauba waxes, which melted at about } 85^{\circ} \mathrm{C}\left(187^{\circ} \mathrm{F}\right) \text {. } \\
\text { There was a homogenous mixture and the mixture was pale yellow in color }\end{array}$ \\
\hline $\begin{array}{l}\text { Adding } 35 \mathrm{~g} \text { coloring agent (Green ketchup) to the mixture and } \\
\text { stirred for about } 10 \text { minutes }\end{array}$ & The mixture was still homogenous but the colour changed from pale yellow to green \\
\hline Burning out ability & The wax burnt out without much residue \\
\hline
\end{tabular}

Table 2. Experiment II.

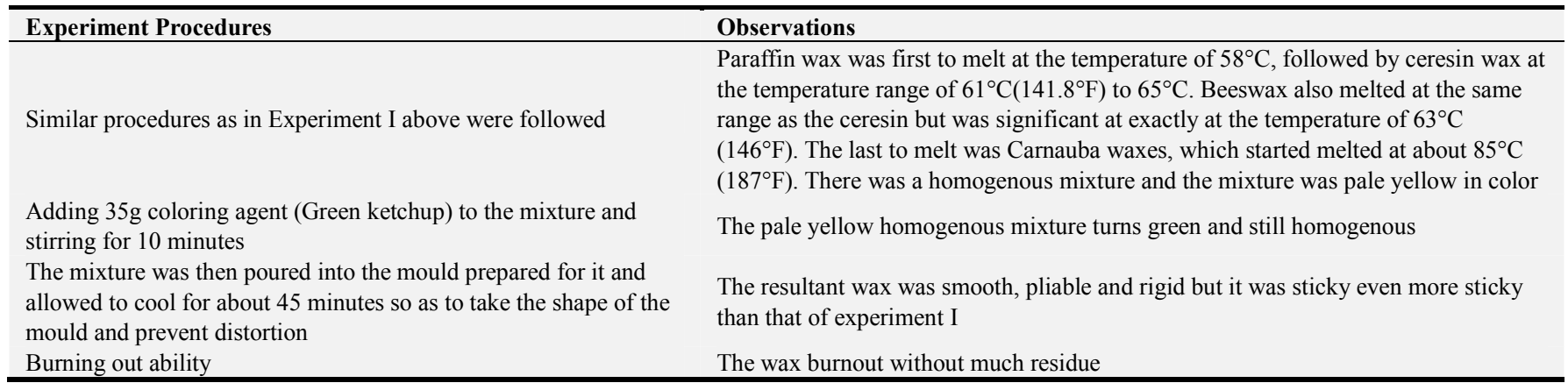

Table 3. Experiment III.

\begin{tabular}{|c|c|}
\hline Experiment III & Observation \\
\hline $\begin{array}{l}\text { Mixing of paraffin wax, beeswax, ceresin wax and carnauba wax } \\
\text { in a beaker and heated in a temperature water bath. }\end{array}$ & $\begin{array}{l}\text { Paraffin wax was first to melt at the temperature of } 58^{\circ} \mathrm{C} \text {, followed by ceresin wax at } \\
\text { the temperature range of } 61^{\circ} \mathrm{C}\left(141.8^{\circ} \mathrm{F}\right) \text { to } 65^{\circ} \mathrm{C} \text {. Beeswax also melted at the same } \\
\text { range as the ceresin but was significant at exactly at the temperature of } 63^{\circ} \mathrm{C} \\
\left(146^{\circ} \mathrm{F}\right) \text {. The last to melt was Carnauba waxes, which started melted at about } 85^{\circ} \mathrm{C} \\
\left(187^{\circ} \mathrm{F}\right) \text {. There was a homogenous mixture and the mixture was pale yellow in color }\end{array}$ \\
\hline $\begin{array}{l}\text { Adding } 35 \mathrm{~g} \text { coloring agent ( }{ }^{*} \text { Green ketchup) to the mixture and } \\
\text { stir }\end{array}$ & The pale yellow homogenous mixture turns green but still homogenous. \\
\hline Burning out ability & The wax burnt out with little or no residue at a temperature of about 400 to $500^{\circ} \mathrm{C}$ \\
\hline
\end{tabular}

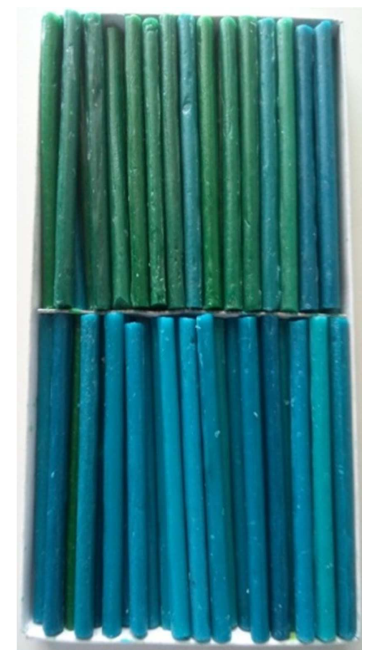

Figure 2. Produced inlay wax.

Part A: Researcher's Observation i. Burning out without residue: the product burns out very well without leaving residue.

ii. Carving to feather edge: the product can be carved to feather edge without flaking out.

iii. Ability to flow: It has the ability to flow very well when molten.

iv. Dimensional stability: has a good dimensional stability and withstands some amount of heat.

v. Luster/Shines: the product exhibits luster quality and gives a shinny surface.

vi. Adhesion: the product has a good adhesion to the model and does not flake out during carving.

vii. Hardness: It is hard enough to be used as carving wax.

Part B: Quality Control Assessment using Evaluation Sheet

Socio-demographic characteristics

Table 4 presents the socio-demographic characteristics of study respondents. As seen, a total of 20 practicing 
Dental Technologists were involved in the study of which $16(80 \%)$ were males while $4(20 \%)$ were females. Amongst the respondents, $10 \quad(50 \%)$ had basic qualification (HND/BSc) while $10(50 \%)$ had different higher educational qualifications. Similarly, the postqualification experience of respondents show that practitioners of 5 years and below were $2(10 \%) ; 6-10$ years were $3(15 \%) ; 11-15$ years $(25 \%) ; 16-20$ years were $3(15 \%) ; 21-25$ years were $5(25 \%)$, and above 25 years were $2(10 \%)$.

Product Evaluation Characteristics

Tables 5, 6 and 7, and Figures 3, 4, 5 and 6 show the results of the properties/characteristics of the product (inlay wax) in terms of smoothness, dimensional stability, and colour stability, as well as flow, burnout ability, pliability and effectiveness respectively.

\section{Smoothness}

As shown in Table 5, two (2) (10\%) respondents evaluated the product to have excellent smoothness; 4 $(20 \%)$ rated it very good; $8(40 \%)$ adjudged the inlay wax to be good; 5 (25\%) assessed it to be average, and $1(5 \%)$ evaluated as poor in smoothness.

\section{Dimensional Stability}

As presented in Table 6, eight (8) (40\%) assessed the inlay wax to be of excellent dimensional stability; 4 (20\%) agreed that it is very good; 5 (25\%) adjudged it good while $3(15 \%)$ evaluated it as average.

\section{Colour Stability}

As seen in Table 7, three (3) respondents (15\%) evaluated the inlay wax to be excellent in colour stability while $9(45 \%)$ adjudged it to be very good; similarly, 7 $(35 \%)$ evaluated it as good, and $1(5 \%)$ assessed it as being average.

Flow ability

Figure 3 showed that $2(10 \%)$ evaluted the product as excellent; 7 (35\%) very good; 5 (25\%) good; $4(20 \%)$ adjudged it average, while $2(10 \%)$ evaluated it as poor.

\section{Burnout ability}

As presented in Figure 4, two (2) $10 \%$ of the respondents evaluated the inlay wax to be excellent; 6 $(30 \%)$ as very good; 7 (35\%) good; $2(10 \%)$ average; and $2(10 \%)$ poor.

\section{Pliability}

As presented in Figure 5, 4 (20\%) of the respondents agree that the product has a very good pliability while 10 $(50 \%)$ assessed it as good; $4(20 \%)$ adjudged it average while $2(10 \%)$ poor.

\section{Effectiveness}

Figure 6 presents the assessment of the effectiveness of the inlay wax.

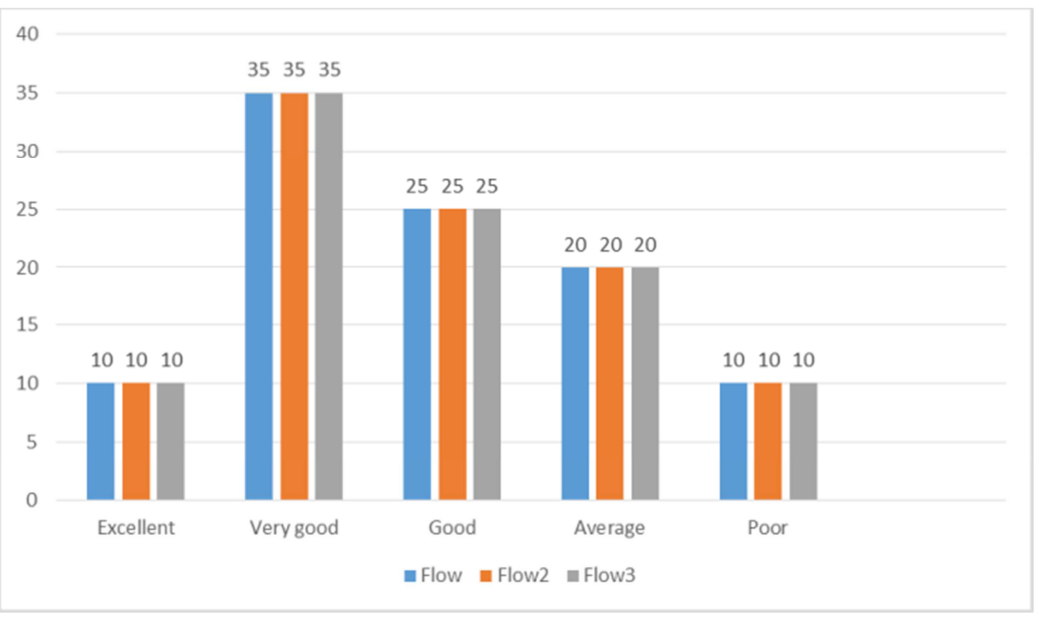

Figure 3. Evaluation of the Flow ability of the product (Inlay wax).

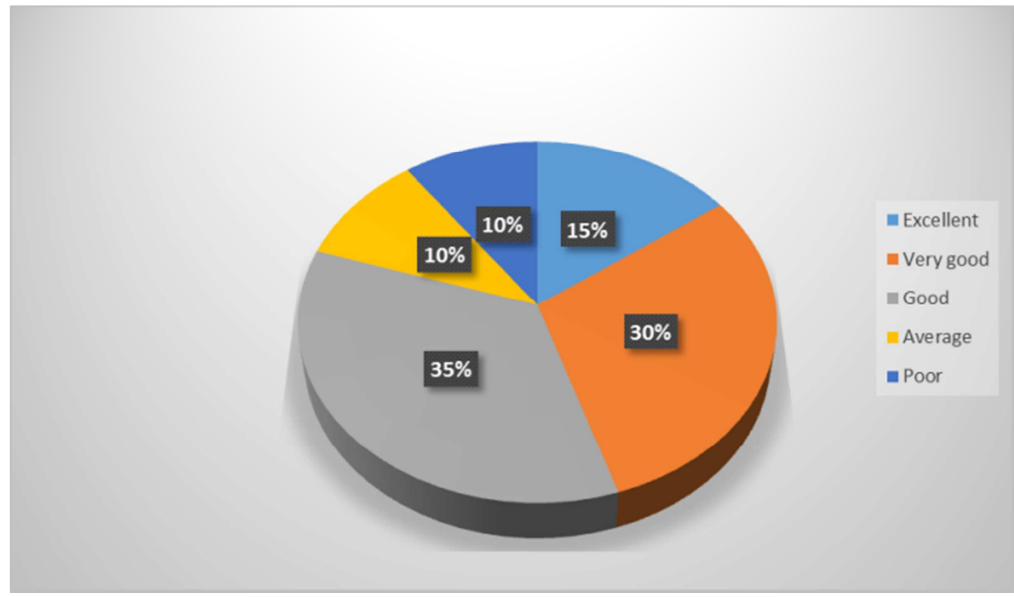

Figure 4. Evaluation of the Burnout ability of the product (Inlay wax). 


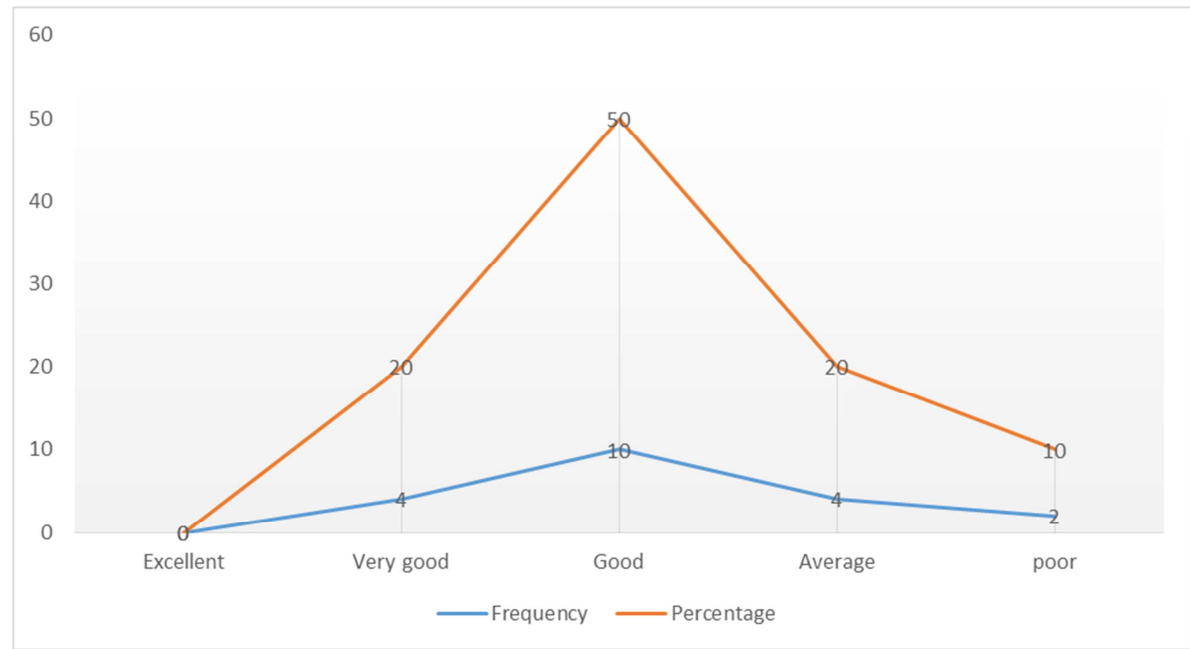

Figure 5. Evaluation of the Pliability of the product (Inlay wax).

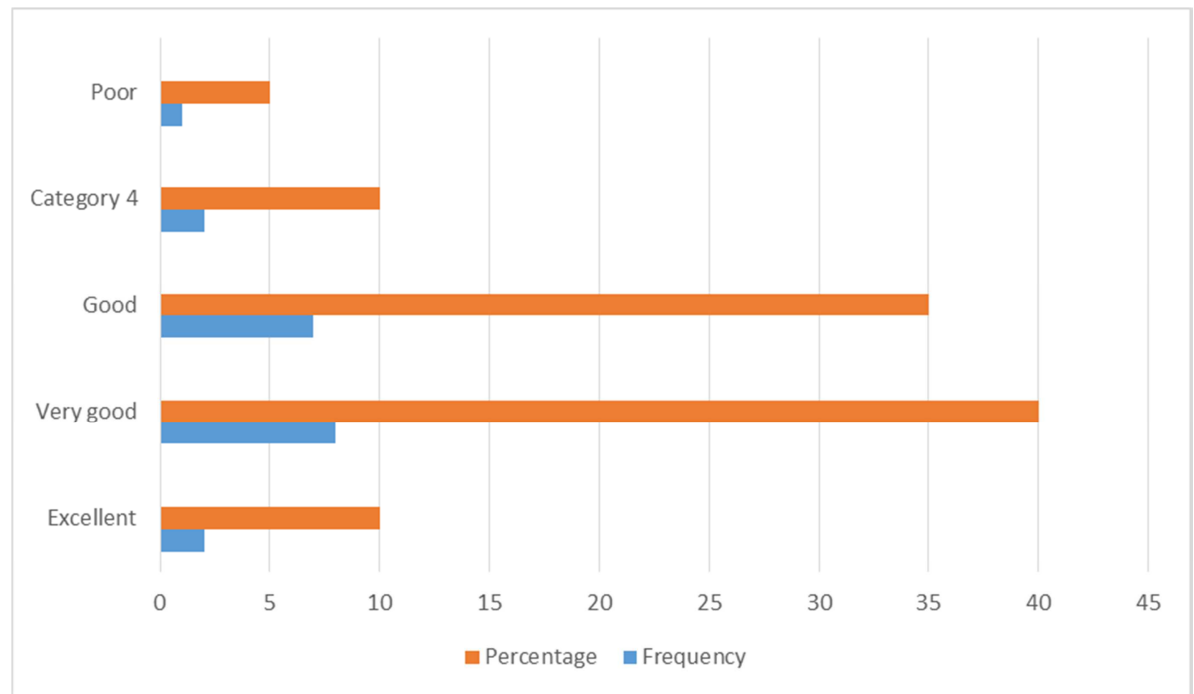

Figure 6. Evaluation of the Effectiveness of the product (Inlay wax).

Table 4. Socio-Demographic characteristics of Practicing Dental Tecenologists.

\begin{tabular}{lll}
\hline Variables & Frequency & Percentage \\
\hline Sex & & \\
Male & 16 & 80 \\
Female & 04 & 20 \\
Age group & & \\
$<$ 26yrs & 02 & 10 \\
26-35yrs & 06 & 30 \\
36-45yrs & 05 & 25 \\
46-55yrs & 04 & 20 \\
56-75yrs & 03 & 15 \\
Marital status & & \\
Single & 04 & 20 \\
Married & 16 & 80 \\
Widow & 00 & 00 \\
Widower & 00 & 00 \\
Level of Education & & \\
PhD & 00 & 00 \\
MSc & 05 & 25 \\
PGD & 05 & 25 \\
HND/BSc & 10 & 50 \\
Years of Experience & & \\
$<5 y r s$ & 02 & 10 \\
\hline
\end{tabular}

\begin{tabular}{lll}
\hline Variables & Frequency & Percentage \\
\hline $6-10$ yrs & 03 & 15 \\
$11-15$ yrs & 05 & 25 \\
$16-20$ yrs & 03 & 15 \\
$21-25$ yrs & 05 & 25 \\
$>25$ yrs & 02 & 10 \\
\hline
\end{tabular}

Table 5. Evaluation of the Smoothness of the product (Inlay wax).

\begin{tabular}{lll}
\hline Smoothness & Frequency & Percentage (\%) \\
\hline Excellent & 2 & 10 \\
Very good & 4 & 20 \\
Good & 8 & 40 \\
Average & 5 & 25 \\
Poor & 1 & 5 \\
\hline
\end{tabular}

Table 6. Evaluation of the Dimensional stability of the product (Inlay wax).

\begin{tabular}{lll}
\hline Dimensional Stability & Frequency & Percentage (\%) \\
\hline Excellent & 8 & 40 \\
Very good & 4 & 20 \\
Good & 5 & 25 \\
Average & 3 & 15 \\
Poor & 0 & 0 \\
\hline
\end{tabular}


Table 7. Evaluation of the Colour stability of the product (Inlay wax).

\begin{tabular}{lll}
\hline Colour stability & Frequency & Percentage (\%) \\
\hline Excellent & 3 & 15 \\
Very good & 9 & 45 \\
Good & 7 & 35 \\
Average & 1 & 5 \\
Poor & 0 & 0 \\
\hline
\end{tabular}

\section{Discussion}

This study carried out in Dental Technology Laboratory of Federal College of Dental Technology and Therapy, Enugu provides information on production of inlay wax using locally sourced materials in Enugu, Nigeria. And the findings are discussed below;

Smoothness: This is a factor for consideration in ensuring good patterns for metallic and others in dental technology practice. This patterns are translated into finished work. The results of this study indicate that locally produced inlay wax is smooth enough as attested to by the Dental Technologists who evaluated the product. The results of this study is consistent with the work of $[16,18,19]$

Dimensional Stability: All dental materials and appliances used in the oral cavity are expected to possess good dimensional stability. The result of this study shows that the produced ideal wax is within the acceptable range of stability. This aligns with $[2,6,16]$

Flow ability: The results of the flow ability as shown in Figure 3 indicate that the locally produced inlay wax is good and can withstand various environments. This is in agreement with acceptable laid down principles [1, 13].

Burnout ability: The results of the burnout ability as shown in Figure 4 indicated also that the locally produced inlay wax, when subjected to heat burns smoothly as in agreement with the acceptable principle laid by $[11,17]$

Colour Stability: The appropriate quantity of the raw materials which were paraffin wax $60 \mathrm{~g}$, Beeswax $5 \mathrm{~g}$, ceresin wax $10 \mathrm{~g}$, carnauba wax $25 \mathrm{~g}$ and $35 \mathrm{~g}$ of coloring agent follows the laid down principle mapped out by [20]

This study is a pilot study and it is believed that if the project is developed further, dental inlay wax can be locally produced in large quantity in Nigeria. The resultant effect of this is availability of the product, affordability of the product, job opportunity and advancement of Dental Technology practice in Nigeria.

\section{Conclusion}

The results of this study, indicate that dental inlay wax can be produced locally in the Dental Technology Laboratory in Nigeria. The quality of the produced inlay wax is of high quality and comparable to the imported/conventional dental inlay wax. The ready availability materials, instruments and equipment, knowledge, and application of the known principles and procedures will go a long way to make Nigeria independent and self-sufficient in dental waxes. Results showed that with the combination of the right principles and materials to locally produce inlay wax aligns with Nigeria's sustainable development plan.

\section{Authors' Contributions}

PCO conceived the study, designed the study and involved in drafting of the manuscript; JE was involved in study design and supervision of the study; COA participated in the experiments and collection of data, SCO participated in the experiment and mould fabrication. GN participated in experiments and data collection; $\mathrm{CSmO}$ was involved in the experiment and supervision of data collection; $\mathrm{KNO}$ supervised the experiment and was involved in drafting of the manuscript. ECO supervised purchasing of raw materials and statistical analysis. All authors read and approved the final manuscript.

\section{Acknowledgements}

We thank the department of Dental Technology, Federal College of Dental Technology and Therapy, Enugu for giving us the opportunity to use their laboratory for the research and also the study participants who were involved in the evaluation of the product. We equally acknowledge the contribution of the President of the Association of Dental Technologists of Nigeria (ADTN), Enugu State Chapter for encouraging its members to be part of the evaluation process of the product.

\section{Competing Interest}

The authors declare that they have no competing interests

\section{Availability of Data and Materials}

The datasets used and /or analysed during the current study are available from the corresponding author on reasonable request.

\section{Consent for Publication}

Not applicable.

\section{Ethics Approval and Consent to Participate}

The experiment was carried out in accordance with the approval of the Ethics Committee of the the department of Dental Technology, Faculty of Health Technology and Engineering, Federal College of Dental Technology and Therapy, Enugu, Enugu State, Nigeria, and all in accordance with the ethical standards laid down in the 1964 as amended in 2000 Declaration of Helsinki. Informed concept was signed by all the evaluating participants (Dental Technologists) before they were allowed to evaluate the product. 


\section{Funding}

No funding was received.

\section{References}

[1] Craig, R; Erick, J. D \& Peyton, F. A. (2010). Restorative Dental Material. Properties of Natural waxes used in Dentistry, $13^{\text {th }}$ edition. B. C Ames Company, Waltham, Mass. 1304-1313.

[2] William, W. C. (2012). Waxes: structure, composition, occurrence and analysis. James Hutton Institute, Invergowerie, Dundee, Scotland.

[3] Manappallil, J. J. (2003). Basic Dental Material, $2^{\text {nd }}$ edition. New Delhi. Jaypee Brothers Medical Publishers Ltd. 29-30.

[4] Endlein, E \& Peleikie, K. H. (2011). Natural waxesProperties, Compositions and Applications. International Journal for Applied Sciences (SOFW Journal).

[5] Stephen, C. B. (2003). Fixed Prosthodontics. Chapel Hill, NC 27514.

[6] Darvell, B. W \& McMillan, L. C. (2000). Rheology of Dental waxes. Dental Material. 16: 337-350.

[7] Jablonski, S. (2005). Illustrated Dictionary of Dentistry, $1^{\text {st }}$ edition. Philadelphia W. B Saunders Company. 868-869.

[8] Anderson, J. (2013), Applied Dental materials, $5^{\text {th }}$ edition, Backwellswentifio publication, Oxford London Edinburgh Melbourm.

[9] Anusavic, J. K. (2010), Philips science of Dental Materials, $10^{\text {th }}$ edition. E. B sounder Company, London.

[10] Taylor, N. O; \& Paffenbarger, G. C. A. (2008). Survey of current inlay casting Techniques. Journal of American Dental Association. 17 (4): 2058 - 2081.

[11] Taylor, N. O, Paffenbarger, G. C. \& Sweeney, W. T. A. (2013). Specification for Inlay Casting wax. Journal of American
Dental Association. 18: $40-52$.

[12] Combe, E. C \& Grant, A. A. (2002). Note on Dental Materials, $6^{\text {th }}$ edition. New York, Churchill Livingston. 196.

[13] Baker, E. A. (2002). Chemistry and morphology of plant epicuticular waxes. In The Plant Cuticle. Ed. DF Cutler, KL Alvin, CE Price. Academic Press.

[14] Nasser, W. E. (2011). "waxes, Natural and synthetic" in Melcetta, John J. Encyclopedia of Chemical processing and Design. 17-67.

[15] Wilhelm, R \& Hermann, M. B. (2005)."Esters, Organic" Ullmann's Encyclopedia of Industrial Chemistry, Wiley-VCH, Weinheim.

[16] Van-Aken, J. (2012). Distortion of wax patterns as Influenced by setting and Hygroscopic Expansion of the Investment. T. Tandheelk. 68: $583-610$.

[17] Phillips, R. W \& Biggs, D. H. (2008), Distortion of wax pattern as Influenced by Storage Temperature and Temperature of Wax manipulation. Journal of American Dental Association. 11:27 - 37.

[18] Parish, J; Terrence, L \& Shengrong, L. (2002). The Chemistry of Waxes and Sterols. In Casimir C. Akoh, David B. Min. Food lipids: chemistry, nutrition, and biochemistry, $2^{\text {nd }}$ edition. New York, M. Dekker. 103.

[19] Freund, M; Mózes, G \& Jakab, E. (2002). Paraffin Products. Properties, technologies \& applications. Amsterdam, $2^{\text {nd }}$ edition. Netherlands, Elsevier. 121.

[20] Warth, A. H. (2007). The Chemistry and Technology of waxes. $2^{\text {nd }}$ edition. Reinhold publishing Company, New York. $2-5$.

[21] Bogdanov, S (2009). Beeswax: Uses and Trade. Bee Product Science. 1-18.

[22] Bogdanov, S (2009). Beeswax: Production, Properties, Composition and Control. Bee Product Science. 1-17. 